\title{
Local Clusters formation for Indian Universities
}

\author{
Mr.Srinatha Karur ${ }^{1}$ and Prof.M.V.RamanaMurthy ${ }^{2}$ \\ ${ }^{1}$ Oracle DBA \& Technical Support, Ibra College Of Technology \\ ${ }^{2}$ Professor \& Director, School of Computer Science, Osmania University
}

\begin{abstract}
:
In this paper we discussed about the concept called "Local clusters" in the Indian Universities point of view. The Indian Universities have different structures which are completely depend on local Government policies. The available Universities are aided by local Government or Semi Government or Private or Central Government .Even though University Grants Commission (UGC) is a decision authority all these Universities are highly influenced by local Government policies. Our aim is integrate these local policies with UGC policies and form a cluster as local Unit.UGC is a autonomous body under Ministry of Human Resources (MoHR)
\end{abstract}

\section{KEYWORDS:}

Local Clusters, Logical Clusters, University Grants Commission (UGC), Datamining tools, Globalization

\section{Introduction}

In the recent years, generally all domains are highly influenced by Clustering policies and procedures. Especially in the field of Education and Business and Commerce the clustering polices have more success rate. Due to the globalization, the Universities and Educational Institutes are moving towards Clustering policies [1].The authors in their publication [6] pointed out the different levels of Clustering are available in the real world [2].The University Information System consists of not only the number of students enrolled in a defined organization and also it tells about past, present and future data. The developing countries like India, the policies are not strongly defined and creation of centralized data base is very difficult. But where as developed countries like USA, UK, Australia,Newzealand it is very easily to create centralized database on the basis of separate protocols or autonomous bodies(E.g.: Australia Research Council) [2].So local clusters are very useful for policy making and technical implementation [3].We can use different Data mining tools and Algorithms for create local clusters in the context of Indian Universities as per guide lines of UGC.For future implementation of defined educational polices we can use both supervised and unsupervised learning polices(Eg: Use Bayes model or Markov chain process for future estimation using given past data and then implement for local clustering).Logical clusters are useful to define the abstracts at different levels. Logical clusters means it may be local or central. Some times local clusters leads to decentralization and anti cluster policy [11],pp 1001-1002. 
Clusters of micro, small and medium enterprises (MSMEs) are found in abundance across the globe. Since the early nineties, cluster based development of MSMEs has been adopted in more than fifty countries. The Foundation for MSME Clusters was conceptualized to contribute towards this process of cluster based development of MSMEs and thus enhance their competitiveness, generate sustainable employment and alleviate poverty. At the suggestion of the Ministry of Small Scale Industries, Government of India, the United Nations Industrial Development Organization (UNIDO) conceptualized and initiated the process of creating the Foundation for MSME Clusters. Subsequently, the Foundation was legally constituted as a nongovernment, non-profit registered trust under the auspices of the Entrepreneurship Development Institute of India (EDI), Ahmedabad, in the year 2005 [12].In India generally different types of clusters are available. They are Industry Clusters, Handloom Clusters, Handicraft Clusters, IT Clusters, Micro, Macro Enterprise Clusters, and Service Clusters etc. In India Economic clusters are not separately defined and it is combined with Industry Clusters by Ministry of Commerce and Industries. List of Industry Clusters are available in their official website [13].All these clusters are constructed as local clusters only. Educational Clusters are partially defined by UGC [4],pp 100,111-112.

Clusters can be local, regional, national or even global. There is some debate about the continuing relevance of location in a world of increasing globalization and instant communication where, it is claimed, geography is no longer so important, and some commentators even talk of the "death of geography". Others claim that globalization is making regional economies, as opposed to national economies, the focus for economic activity (Martin and Sunley, 2003).

\section{OBJECTIVE}

Our research objective is estimate the nature of local clusters for Indian Universities using different developed countries cluster policies and different case studies across the world. After getting the clusters the data should be Visualize with supported tools. Supervised methods are applied wherever necessary condition takes place.

\section{Related work}

\subsection{Estimation of Local clusters with respect to USA,UK and other theories}

In India as per UGC list there are totally 611 Universities are available. All these Universities are working under different modes. Mainly there are 4 modes are available. They are local Government, Central Government, Indian Institute of Technologies, National Importance Institutes (Previously REC),Deemed Universities, and Private Universities [4]UGC 12FYP(Five Years Plan) deals or expects the number of enrollments in next five years ie 2012-2017 [4] pp-9 . All state wise Universities are available as local clusters [4],pp 11.

Geographically we can divide the number of nodes on the basis of direction ie South, North,West ,East and North East. But this is OPTIONAL case. We can move local clusters to central and vice versa on the basis of Move Results(MV),Move Models(MM),Move Data(MD) [5],pp-2.The success of local cluster is completely depend upon lot of local parameters and central parameters. Most precautions are necessary to construct the local clusters other wise they 
will become autonomous or failure clusters. We can use Papyrus model for distribute the data for mixed strategies [5],pp 9.

Authors randomly took some sample locations as nodes from different locations ie South, North, East, West and Northeast. Authors selected 30 Random locations from all over India and created cost matrix and linear projections and constructed Algorithms for node creation [6] pp-134137.All sample nodes are tested with Association Rules(Minimum support 0.18 and Confidence 0.8 ) and Naive Bayes with Confusion Matrix [6],pp-138.Authors used different tools like Tanagra,Weka,R,Ggobi and Gephi etc. Create separate Data Mining model for this 30 nodes using XML like language and then communicate with Centralized database [5], pp 6.

Create XML like and RDBMS database for local clusters as per context we can use both type of databases.30 different nodes have different sub nodes which forms different binary trees and we can use specified algorithms for path creation and trace with IN,POST and PRE order algorithms.UGC in its 12th FYP expected that approximately 40,000 colleges are going to clustering as per need of enrollment. It is not possible to take all available Universities and Colleges. It is assumed that 30 nodes are considered on the basis of direction (ie South,North,East,West,NorthEast) in such a way that all directions have NOT NULL values. Authors used Tanagra and Orange tools for Hierarchical model (Wards linkage) with height 10 and 0.73 etc. [6], pp 139.

In the modern, globalized world economy, regional clusters of related industries (rather than individual companies or single industries) are the source of jobs, income and export growth. These clusters form "value chains" that are the fundamental units of competition in the global economy [14],pp 2.All tested 30 nodes are local nodes only as per requirement and definition of local clusters(Eg: South Clusters, North Clusters, West Clusters etc).

Let $\mathrm{N}=30$ (nodes), and all these nodes are Uniformly distributed in all specified directions with common database. Authors specified prototype database for this University Clustering system as abstract model [6] pp-135. Mathematically when local systems are activated then abstract systems are separated [15],pp. 1.

Local clusters are implement in any domain with respect to global economy and feasible Governance [16],pp 8-9,11.In terms of technical and policy based the authors are already discussed in their publication [6],pp 135-136.

For local clusters only country level or University level clusters are used. Continental level clusters are out of scope of local clusters [6],pp. 128-131.For economic clusters USA Universities are treated as standard case studies [6],pp 129.For Research clusters Australian Universities are considered as standard case studies [6],pp 131-133.

The factors which are considered during the construction of local clusters are localization, local industries [17],pp 2-3,local economics, local demand [17],pp 6-7,local competition for inputs and out puts[17], pp. 8,local customer base[17],pp 9,local buyer, local competition, local resources[17],pp 10, etc are treated as given parameters for industry and University bi-clusters All 5 directions(South,North,West,East and NorthEast) are different local clusters. Within these

local clusters(n), defined number of sub local clusters are available(m), with condition that ' $\mathrm{n}$ ' has root node and ' $m$ ' is always child. 
Labor Statistics has made projections of growth by cluster,giving a hint as to which clusters may be able to continue to do this. Based on these national projections, some clusters,such as Commercial Services and Health Services, are expected to create far more inner city jobs than others, making them attractive candidates for development [18],pp 04.

\subsection{Implementation of local clusters for proposed system}

Our aim is to construct the local clusters with abstract form.After central database is ready the local systems prepare prototype model then communicate with central databse either in the form of RDBMS or XML.It is assumed that for construction of local clusters the communication between local and central (Global) Governance is holds good.

a) ForSouth direction take randomly any number of nodes say South nodes( $\mathrm{S}$ nodes $>0$ ), and form local clusters is as follows. If $a[i j]=1$ then path is created else no path. So mathematically if $F(x)=a i j=1$ then path is formed between $i$ and $j$ (Returns to local cluster), and $i$ is NOT EQUAL to $j$

Else no path between nodes(Returns NULL or autonomous OR garbage values)

b) Repeat the above process for all sampling nodes which are available in South direction. The above process should be implementing for all remaining nodes in remaining directions.

c) Identify the nodes which are free from path. Collect all the free nodes for further iteration and repeat the above step until all nodes are available in the tree. Let the remaining free nodes are k-nodes.

d) Form XML like database with these K-nodes and RDBMS with remaining N-K nodes.

e) Confirm these two databases as local database or local cluster and formed 2 cluster systems. One is RDBMS AND another is XML LIKE databaseCommunicate with these databases using explicit methods or with Centralized systems [5],pp-6-7.

f) Using Cluster Diamond frame work (CDF) we can form Centralized system [7],pp 297.

It was found that Universities played a central role for driving and sustain a clusters in different domains [7],pp-301. CDF mainly deals about Networks, Business, Infrastructure, Knowledge movement, Innovation hubs etc [7],pp 299. 


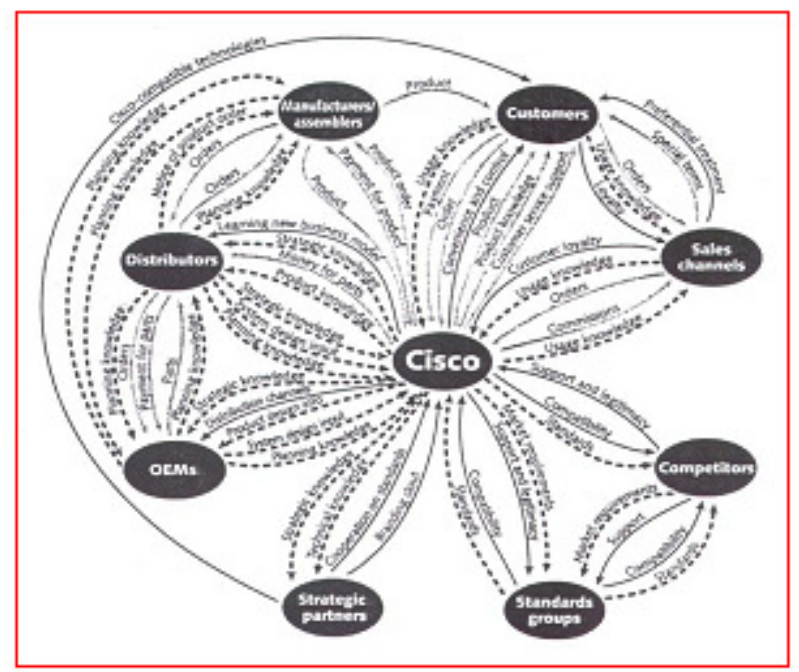

Fig. 1 A topology of a virtual cluster (source: Tapscott, Ticoll. and Lowy 2000)

g) Separately create networks for all 30 sample nodes on the basis of local clusters (ie South, North, East,West) etc. and separate with each other and form abstract Models. After forming the abstract models, local models are communicate with Centralized model for deactivate the abstract model and convert the real time application.

\subsection{Algorithm for proposed system(Local clusters)}

The number of nodes are geographically separated and have its own identity and distinct. The distance matrix is already calculated by authors in their publication [6],pp. 136.It is assumed that Chennai location is treated as root node for South direction and applied projections [6],pp. 137.In terms of Association rules it gave 10 rules with minimum support 0.15 and confidence 0.9 [6],pp. 137.Repeat the above steps with respect to different directions with respect to distinct geographical locations(Hyderabad,Chennai,Bangalore etc. as South group).It means that the centralized system became decentralized system and tends to local systems. The below table gives the clear picture of local clusters.

Table 1. Shows sampling from each local area

\begin{tabular}{|l|l|}
\hline \multicolumn{1}{|c|}{ Direction } & Number of nodes \\
\hline South & 6 \\
\hline North & 6 \\
\hline West & 6 \\
\hline East & 6 \\
\hline North East & 6 \\
\hline Total & 30 \\
\hline
\end{tabular}




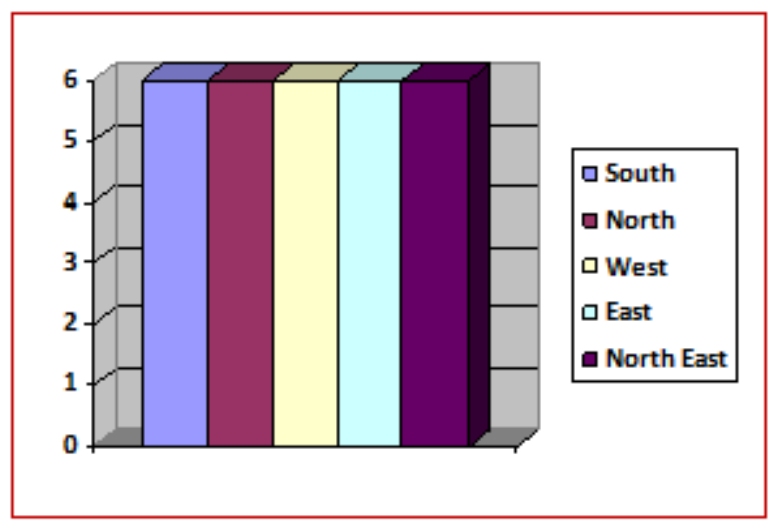

Fig. 2 Centralized system became local systems(Source Mr.Srinatha Karur and Prof.M.V.Ramana Murthy 2013)

The local systems consists of geographical clusters, technical clusters, economic clusters, industry clusters, logical clusters, physical clusters, educational clusters etc. The logical flow between either local or central systems is established either statically or dynamically. This logical flow may or may not form logical clusters. The aim of this logical flow is create local clusters but not logical clusters. In each local system there are any number of sub local systems are available. Generally sub local systems are acted as child or children from parent node to form binary tree. Using data structure's either linear or nonlinear we can store the information of nodes. The cluster centers are purely acts as local systems and returns NULL value to centralized database [6],pp. 130.

For South direction consider Madras University as root node and remaining nodes are treated as children.Eventhough separate databases are available for remaining sub nodes all these are treated as sub local systems and free from primary key. Only root node consists of primary key and must distinct. Repeat the above process for XML like database also. In real time data is either RDBMS OR XML OR any other type. The University system consists of all types of data including audio and video type also. In this context only either RDBMS or XML should be considered for Data mining techniques. Generally student_id is treated as primary key and stored in root node permanently.

The authors implement clustering technique or any data mining technique on these sample nodes only. In real time the number of Universities are 611 and 31,324 affiliated colleges are available [4],pp. 9.From South region totally 165 Universities are available [4],pp. 11. The below table gives clear picture of sampling from South region. 
International Journal of Artificial Intelligence \& Applications (IJAIA), Vol. 4, No. 5, September 2013

Table 2: Shows the number of nodes available in South zone as local nodes

\begin{tabular}{|l|l|l|l|}
\hline SNo & Name of State & Total size & Sample size \\
\hline 1 & $\begin{array}{l}\text { Andhra } \\
\text { Pradesh }\end{array}$ & 45 & 1 \\
\hline 2 & Kamataka & 41 & 1 \\
\hline 3 & Tamilnadu & 59 & 1 \\
\hline 4 & Kerala & 16 & 1 \\
\hline 5 & Goa & 1 & 1 \\
\hline 6 & Pandecherry & 3 & 1 \\
\hline 7 & Total & 165 & 6 \\
\hline
\end{tabular}

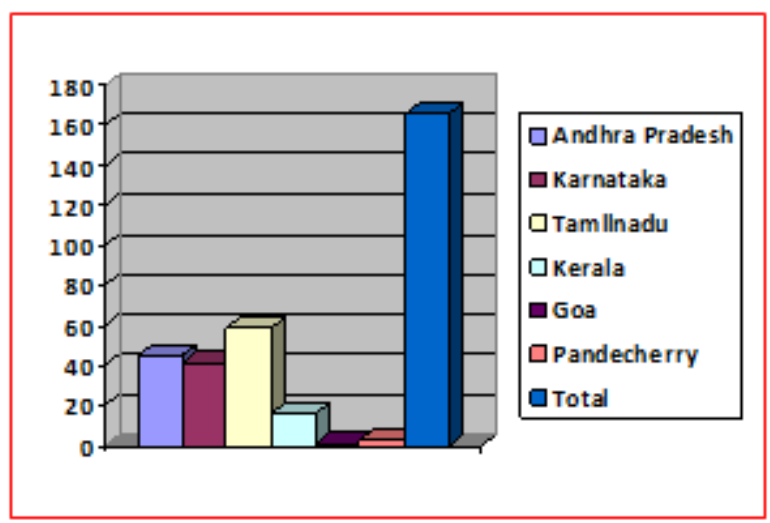

Fig. 3 Total number of Universities in South Region(N=165)

The above Fig: 3 indicates that A.P state has 27\%,Karnataka has 25\%,Tamilnadu has 36\%,Kerala has $0.06 \%$, Goa has $0.006 \%$ and Pondicherry has $0.018 \%$ sample from size of 165 .

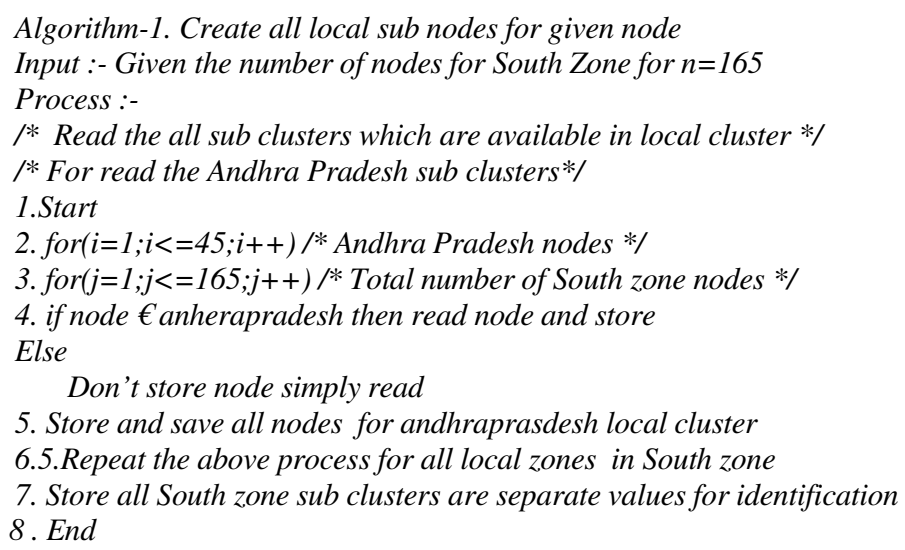

Repeat the above algorithm for all remaining zones ie South,North,East,West and South North and store all values are separately depend upon distinct zone values. The different zone values for all local clusters are constituted roughly defined set. 


\subsection{Detail implementation of local nodes with Datamining tools}

Lot of data mining tools are available for implementation of proposed system with 30 nodes sample.Datamining tools are available in the form of freeware and shareware. Orange,Weka,Tanagra,Rapidminier, $\mathrm{R}$ etc are some of the popular freeware tools[19].Pure statistical tools are also available. But all important Statistics methods are available in almost data mining freewares.

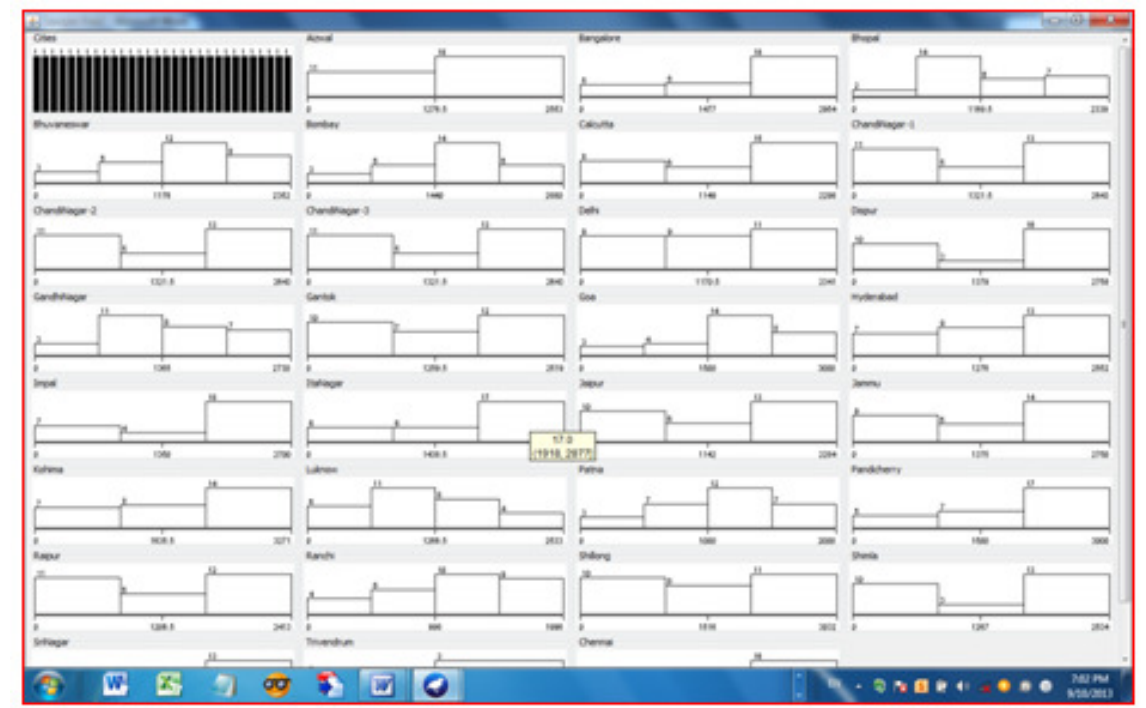

Fig. 4 Weka implementation for all 30 sample nodes(Visualization) with available frequencies.

From the above Fig 4 it is noted that for each and every city is has its own interval. By considering the mid point we can easily found that the number of cities are available between that interval. In the case of Chennai 3 local clusters are available for its interval [0,3032].The exact two partitions of interval is $[0,1516]$ and $[1517,3032]$. Now we can easily find out how many cities are available near by with this two intervals. For interval $[0,1516]$ two sub clusters are available and between $[1517,3032]$ one sub cluster is available. The interval $[0,1516]$ is once again has sub intervals. Here in this case at interval $[0,1010]$,ten cities are available and from $[1011,1516]$,eight cities are available. In this way we can easily find out the sub clusters as KNN method. 


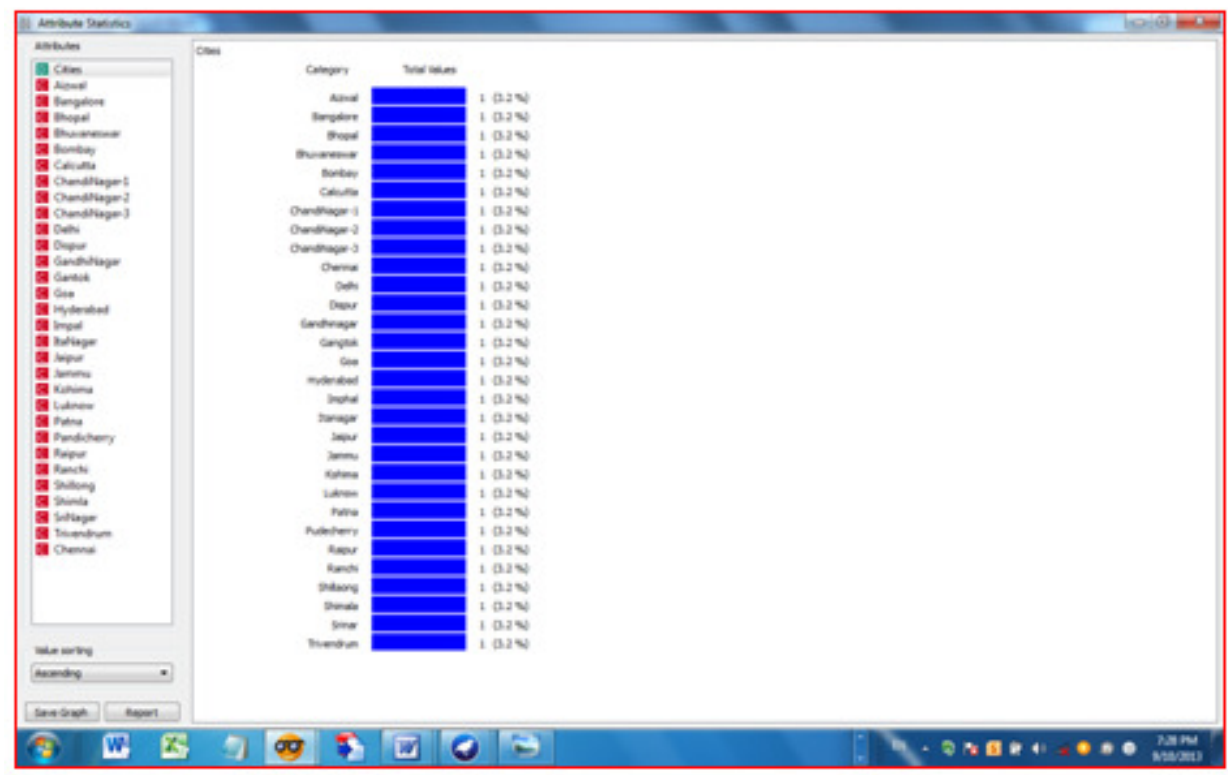

Fig. 5 Attribute Statistics of 30 nodes sample(Orange implementation) with available percentage.

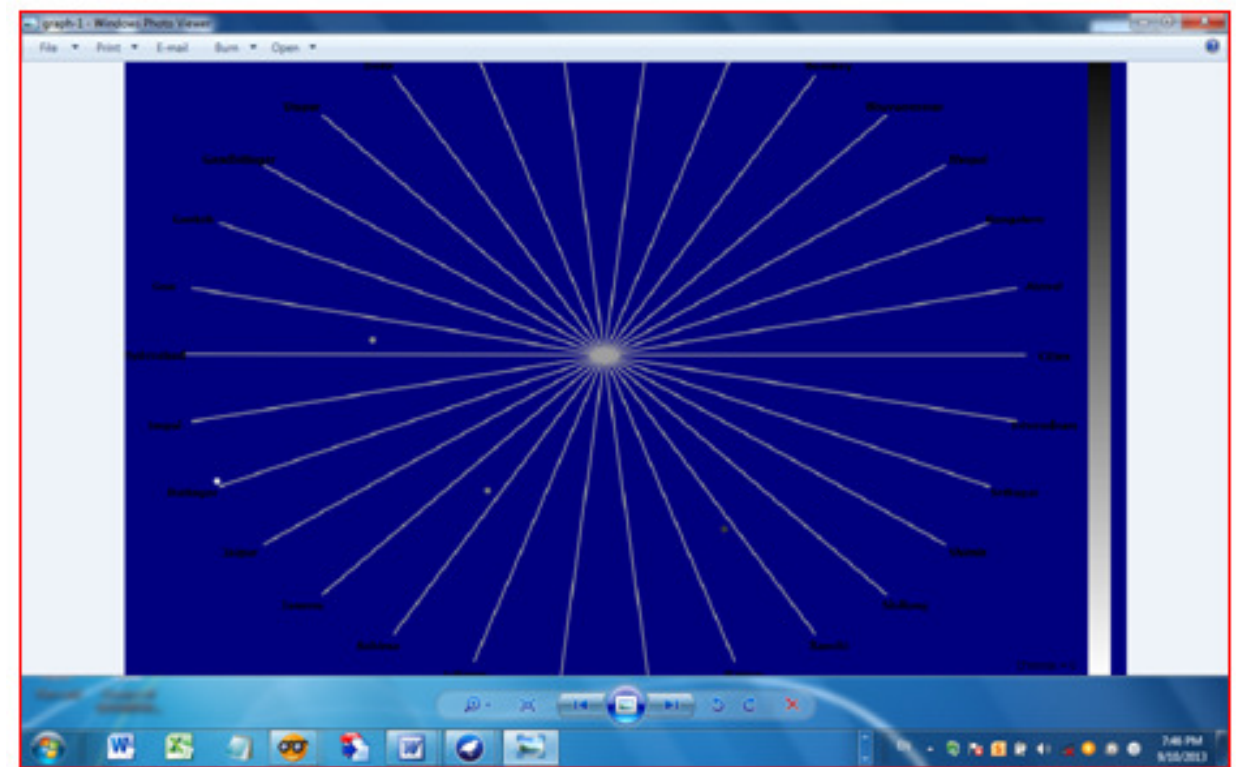

Fig 5. Shows all projections with respect to Chennai as root node,Right side scale is available

The above procedure is repeat for remaining n-1 times and we can get different linear projections. In this Fig 5 Chennai node is hidden value. With this hidden layer we can form Neural networks for this projection. Chennai node scale value is available between 0 to 2815. The above projection is available for show all option in Orange tool Linear Projections. Here we have two types of optimization Dialogs are available. They are VizRank and FreeViz.We can not apply VizRank because Chennai is Continues class. So we can not evaluate the projections. But we can evaluate FreeViz method for evaluation of projections. For this we have Linear, Square,Guassian,KNN,Variance methods with Circle, Random or Manual options as anchor 
positions. The above projection has implemented with Gaussian method with Circle anchor position. We can repeat the above process for remaining methods and anchors.It is observed that there is no change in Chennai scale value ie between 0 to 2815 .

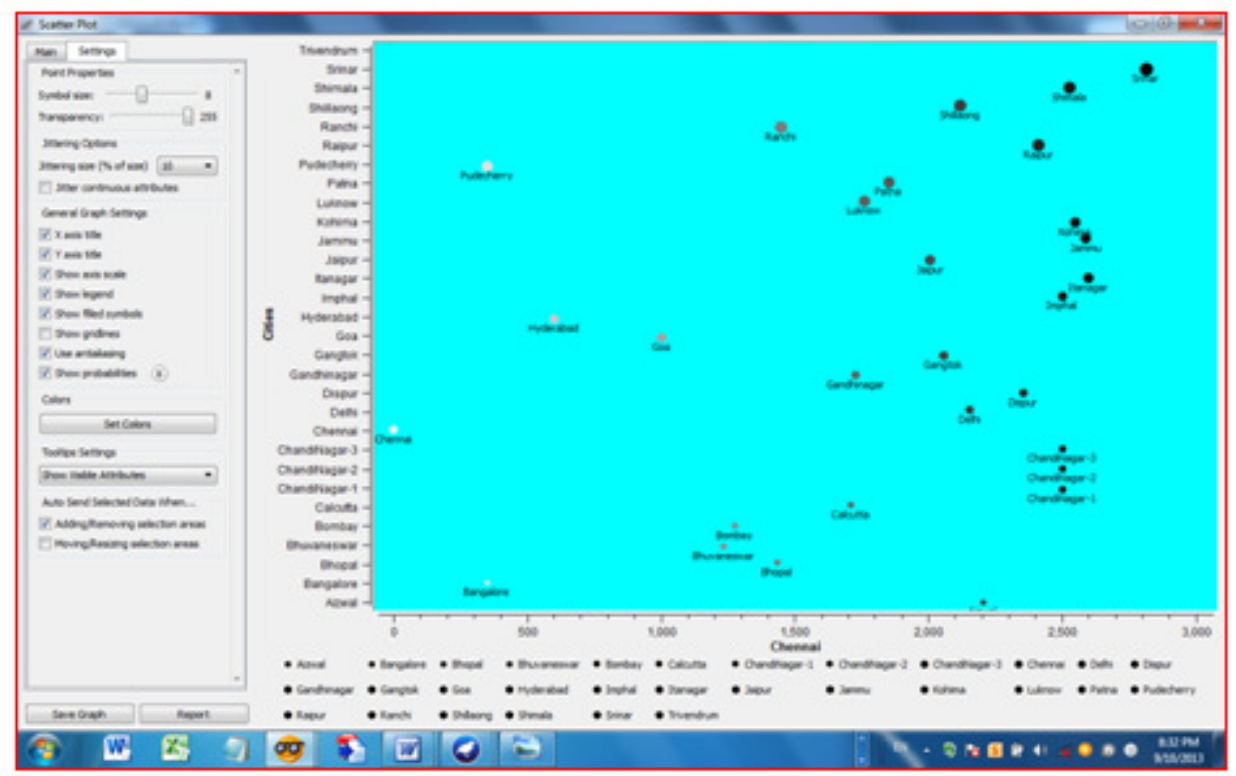

Fig 6. Shows Scotter plot between Chennai node and remaining nodes with VizRank

Along the $\mathrm{X}$-axis Chennai node is available and along the $\mathrm{Y}$-axis remaining 29 nodes are available. Here we can not evaluate projections due to lack of FreeViz.In this case only VizRank is available. The various attributes are available for point attribute for different visualizations. The different attributes of point are label, size, and shape.

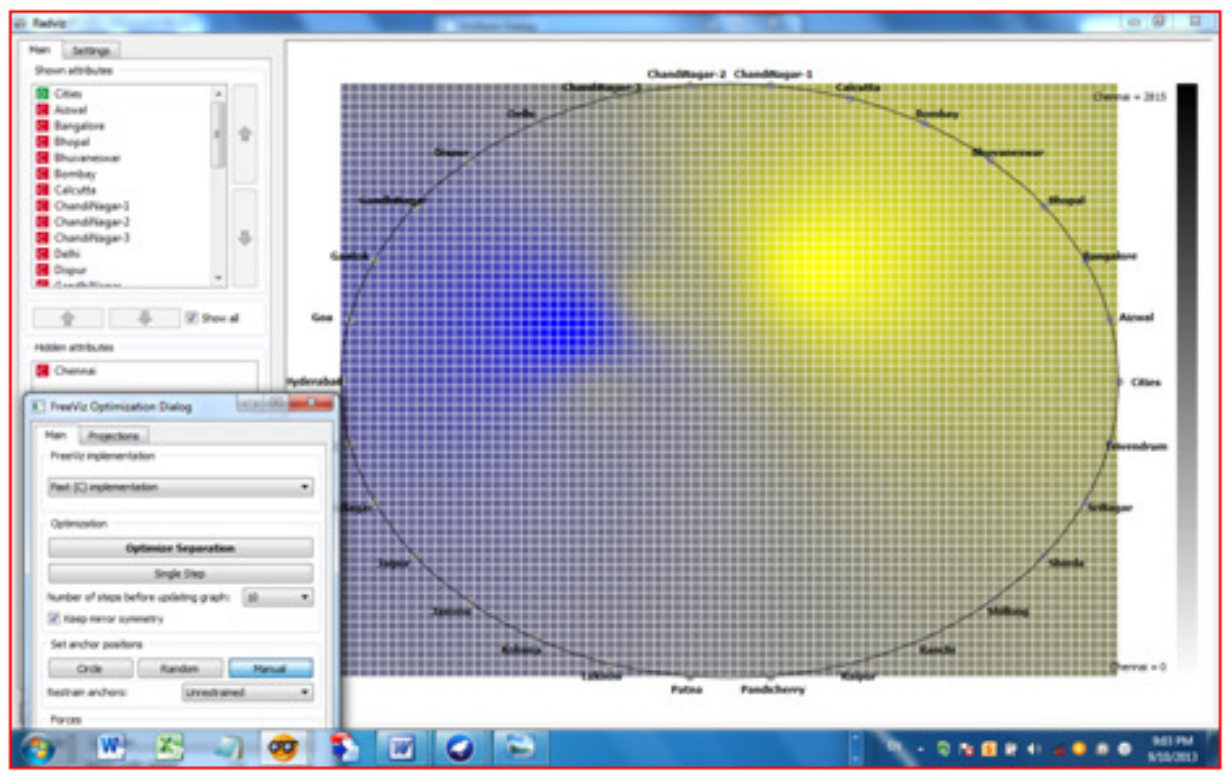

Fig 7. Shows RadViz projection with Circle option with Gaussian law 
The RadViz projection consists of mainly 3 options like Circle, Random, and Manual with different methods. They are Linear, Square, Gaussian, KNN, Variance methods or laws. We can implement RadViz projection with Circle with Gaussian or Random with KNN law. If we apply Circle option with Gaussian law the locations are available side by side as shown in Fig 7.We can apply any combination and examine the nature of nodes. In this figure Chandigar-1,Chandighar2,Chandighar-3 are located side by side with respect to legend node Chennai as shown in Fig 7.

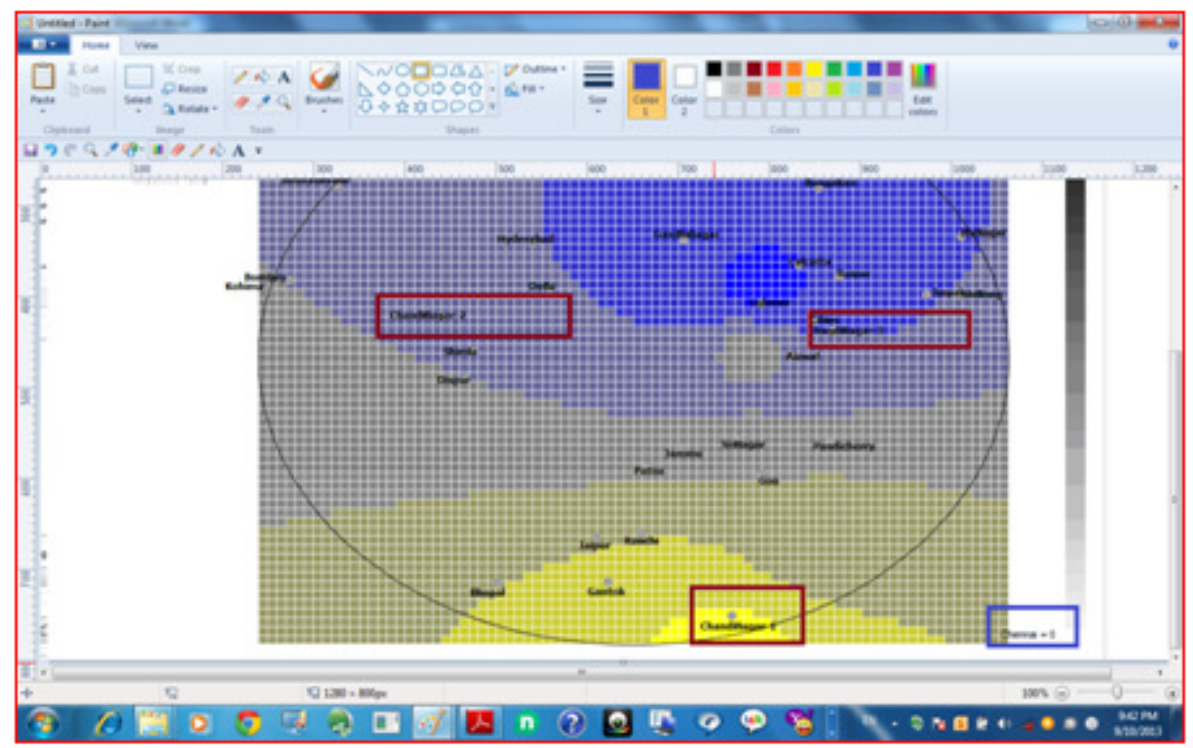

Fig 8. Shows RadViz projection with Random option with Gaussian law

In the above Fig 8 the locations namely Chandighar-1,Chadighar- 2 and Chandighar-3 are located in different locations due to Random option with Gaussian law with respect to legend node Chennai.

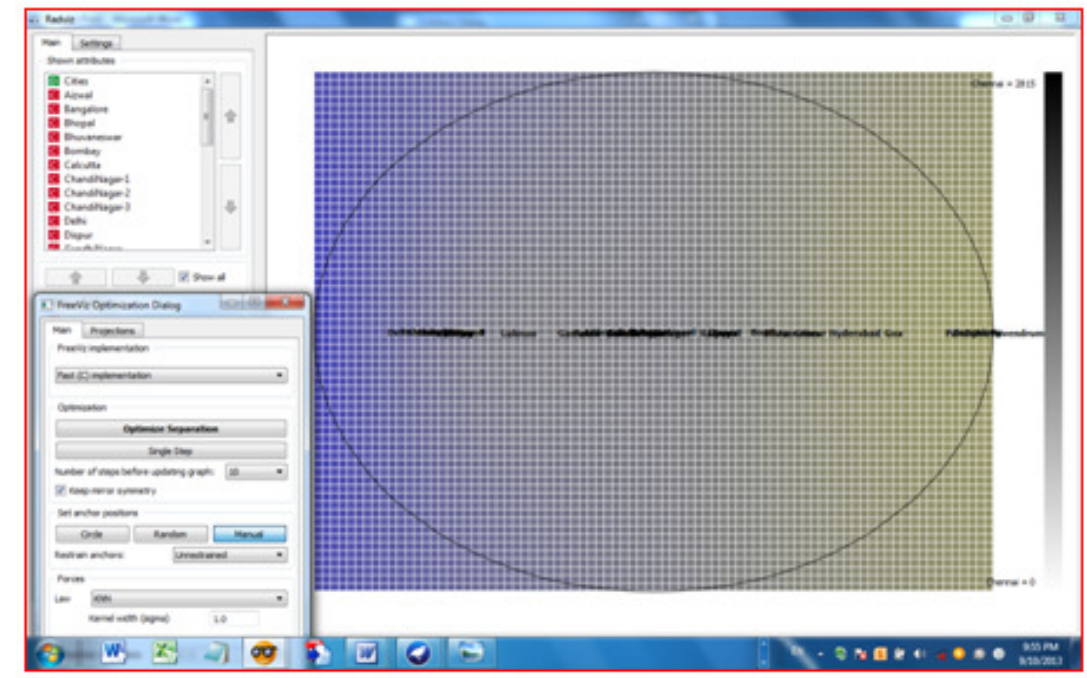

Fig 9. Shows RadViz projection with Circular anchor and KNN law. 
The anchor Circular option with KNN law should not give any effective projection, and we can neglect this combination since all nodes are almost mixed with each other as shown in Fig 9.Chennai is act as legend node or root node to remaining n-1 nodes.

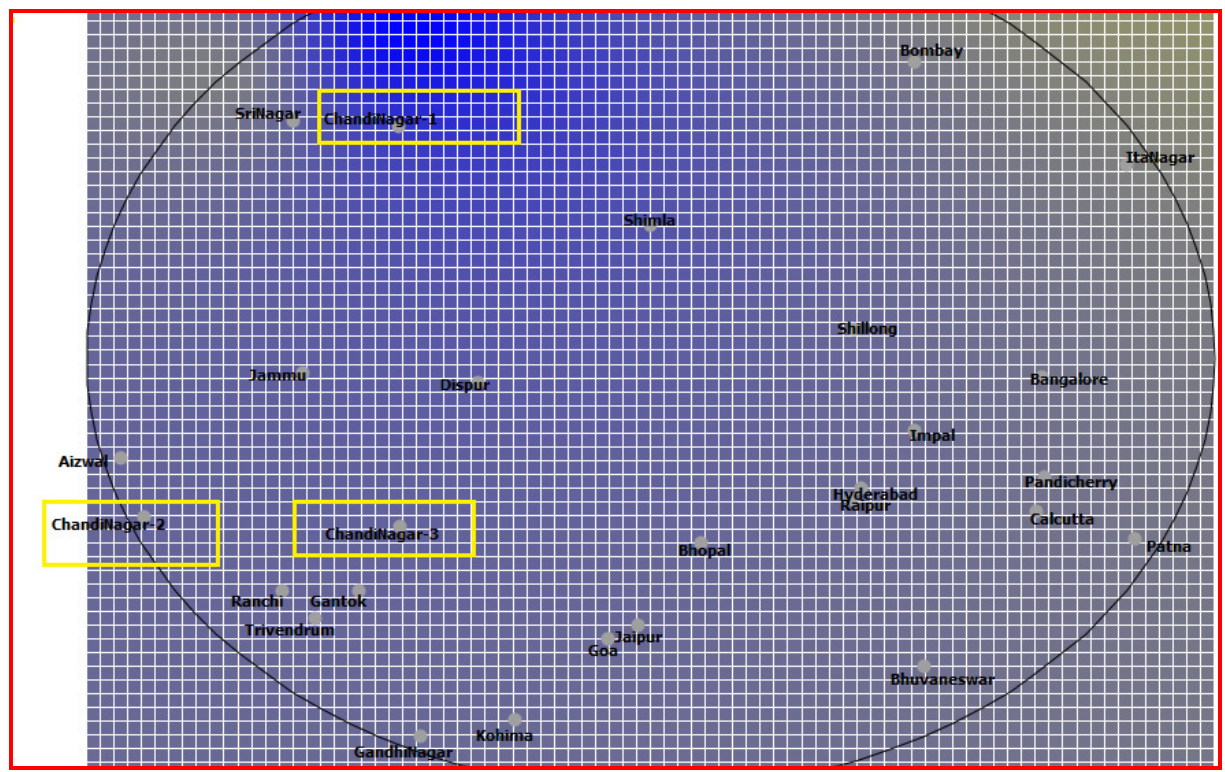

Fig 10. Shows RadViz projection with Random anchor and KNN law.

The Random anchor with KNN law consists of the 3 nodes called Chandighar-1,Chandighar-2 and Chandighar-3 are located in different locations as shown in Fig 10, with legend node Chennai.In this case all nodes are distributed Randomly and well definably as shown in Fig 10.Chennai node is act as legend node.

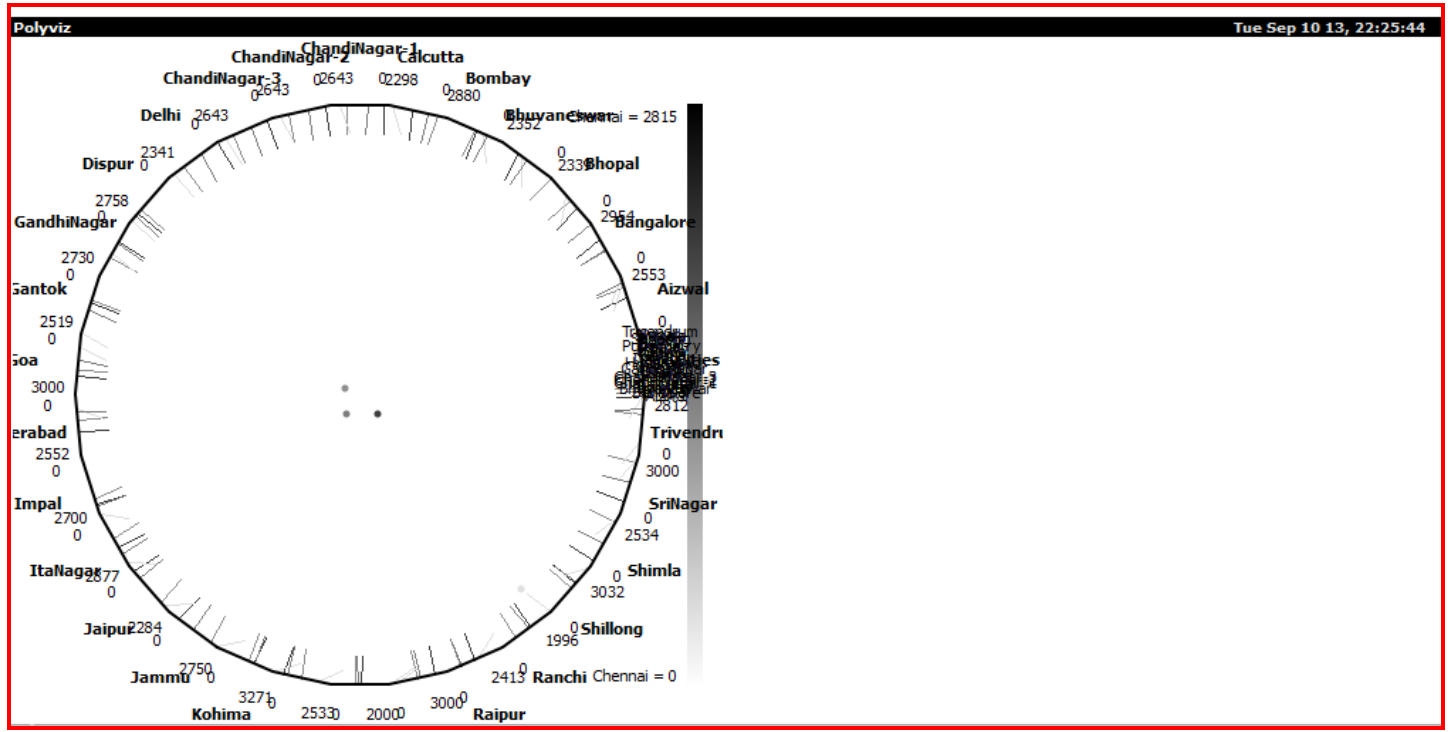

Fig 11. Shows Polyviz projection with VizRank with Chennai as legend node 
From above figure it is found that at almost mid point of Chennai the nodes are repeat or mixed with each other due to one cycle is over from A-Z alphabetically ie from Azwal to Trivendrum.Here the main graph settings are show legend(Chennai node) and Show probabilities are enabled. Any VizRank optimization method is free from projection analysis and read only.

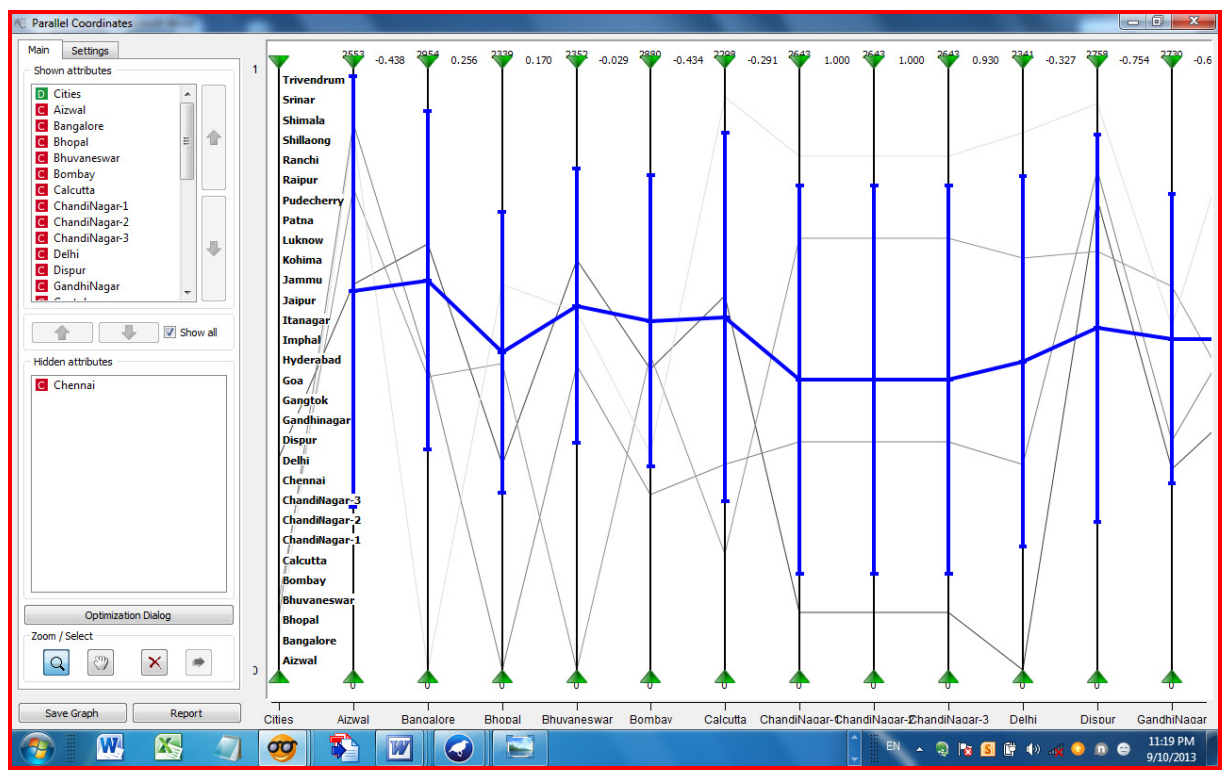

Fig 12. Parallel projection coordinates with Statistical values as Means and Deviations.

In the above figure Chennai is hidden node and Statistical values are Means and Deviations. Middle labels as correlations. For example the node called "Azwal" has Statistical values between "Chennai" and "Trivandrum" nodes. The same procedure is repeated for remaining n-1 nodes and Chennai as hidden node.Now we can estimate Optimizations for minimum, and maximum subsets of given set ie $n=30$.

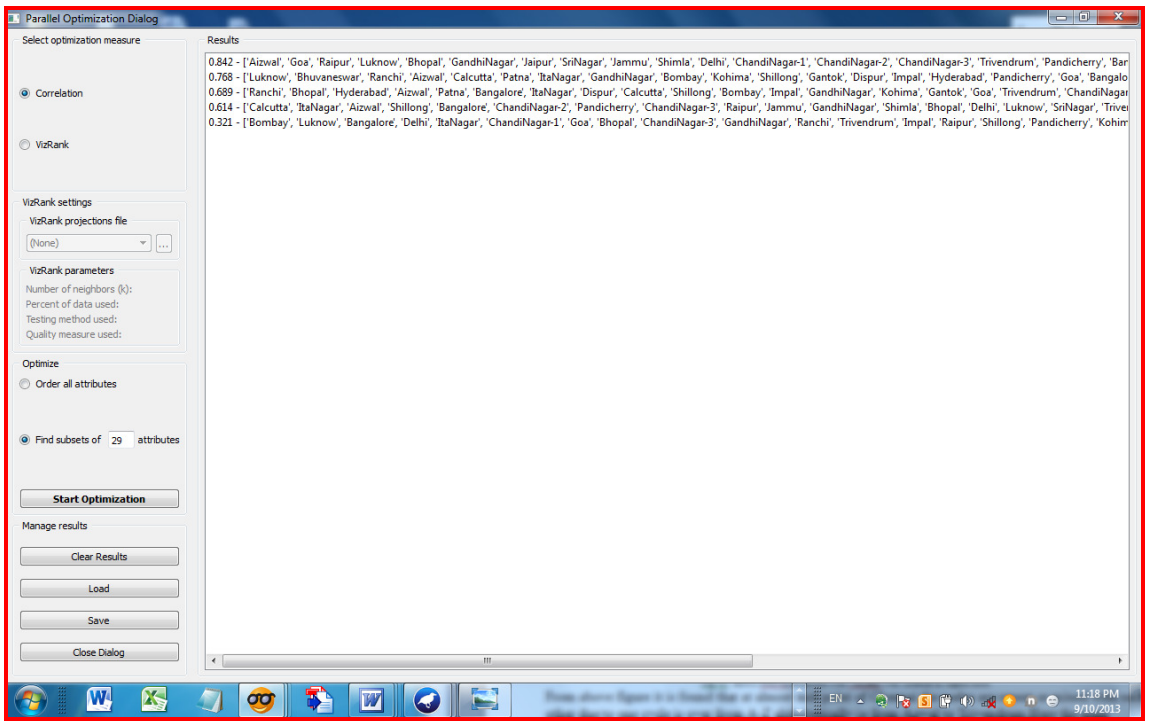

Fig 13. Shows Parallel projections with optimized testing with n=29(Maximum). 
The above diagram shows us there are 5 subsets are formed with $n=29$.It means that all above subsets are available at defined interval or value.We can easily estimate optimized method for Minimum nodes.First node and last nodes are extreme values.We should not get any subsets for $\mathrm{n}=1$ and $\mathrm{n}=30$ (Maximum in this case)any number of subsets.Generally for Minimum and Maximum values of subsets the procedure should be implemented as a definite testing. The same procedure should be repeated for $n=2$ ie for

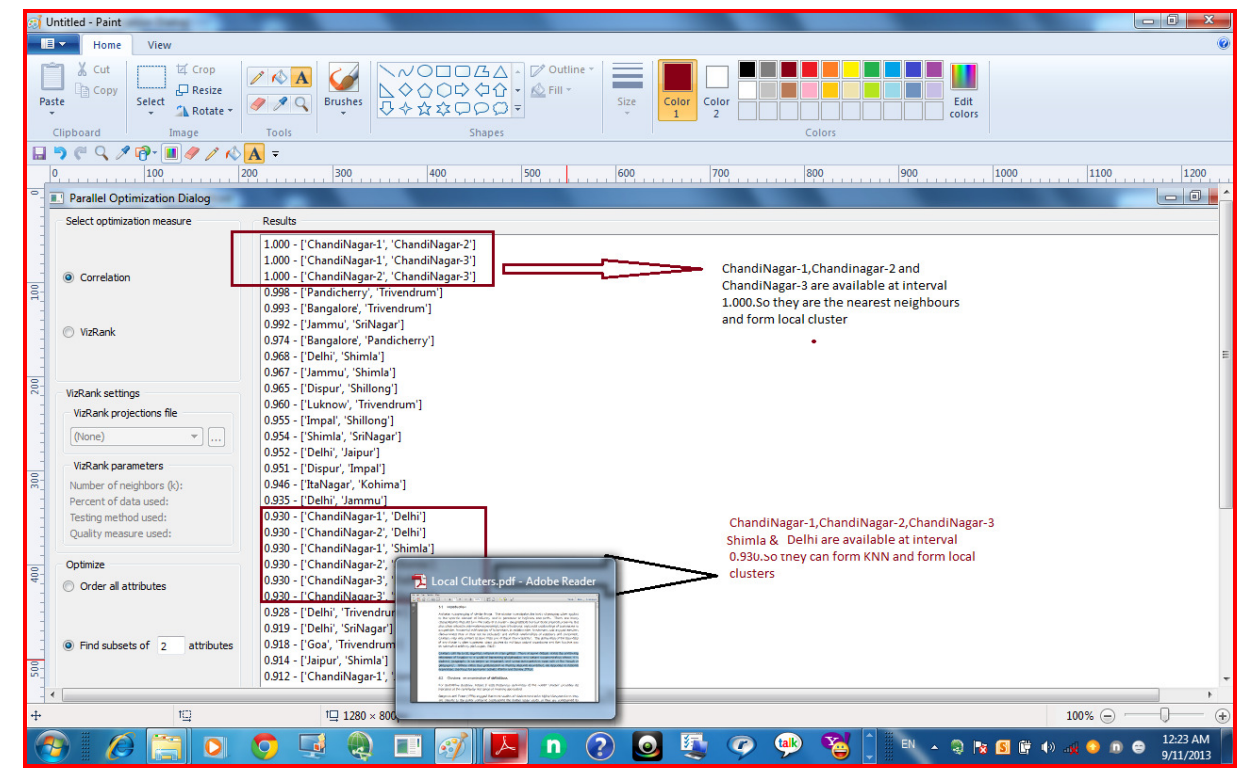

Fig 14. Shows Parallel projections with optimized testing with $n=2($ Minimum).

From the above diagram it is noted that there are lot of subsets are available with $n=2$ at different time interval values. Take accuracy of upto 4 digits without rounding the value.Choose that nodes as nearest neighbors for local clusters. Repeat the above process for all available subsets with respect to their time interval and form KNN cluster tree.

\section{Implementation of local clusters for University Clustering(South India)}

Since we considered the South sample and totally 165 Universities are available in South direction.But our sample nodes are totally 30 only.From South only 6 nodes are available in such a way that each and every state gives its one representation.On the basis of local clusters the various States with in South region get as follows. 
International Journal of Artificial Intelligence \& Applications (IJAIA), Vol. 4, No. 5, September 2013

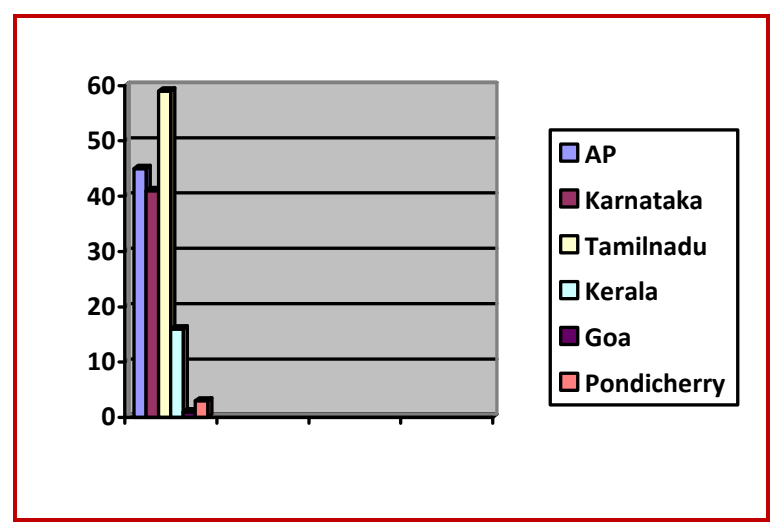

Fig 15: Shows local nodes to South zone Unit with total 165 nodes.

\subsection{Statistical Analysis for minimum number of nodes for South Zone}

For any sample testing minimum 50\% data is required.So in South zone total 165 nodes are available.Take $50 \%$ of nodes as learning sample ie 83 nodes are necessary to do the learning process.Apply the same process for all local levels then the table 2 become like this.

Table 3: Shows $50 \%$ sample retrieved from available size $n=165$.

\begin{tabular}{|c|c|c|c|c|}
\hline Sno & Name & Total nodes & $\mathbf{5 0 \%}$ of size & $\begin{array}{c}\text { Remaining } \\
\text { nodes }\end{array}$ \\
\hline 1 & Andhrapredesh & 45 & 23 & 22 \\
\hline 2 & Karnataka & 41 & 20 & 20 \\
\hline 3 & Tamilnadu & 59 & 30 & 30 \\
\hline 4 & Kerala & 16 & 8 & 8 \\
\hline 5 & Goa & 1 & $0.5(1)$ & $0.5(0)$ \\
\hline 6 & Pondicherry & 3 & $1.5(2)$ & $1.5(1)$ \\
\hline
\end{tabular}

All values are rounded to nearest integer for construct the node but not for idle node.In case of Goa $50 \%$ of sample is not possible to construct the node.So 1.5 as rounded to nearest integer 1.Similary for Pondicherry also rounded to nearest integer for construct the node.It is observed that from table 3 we can covert the data into datamining language as supervised learning .

The authors prepared data using [6],pp. 9 which combines with minimum 50\% availablily assumption of South zones as described in table 3.The datasheet is as follws. 
International Journal of Artificial Intelligence \& Applications (IJAIA), Vol. 4, No. 5, September 2013

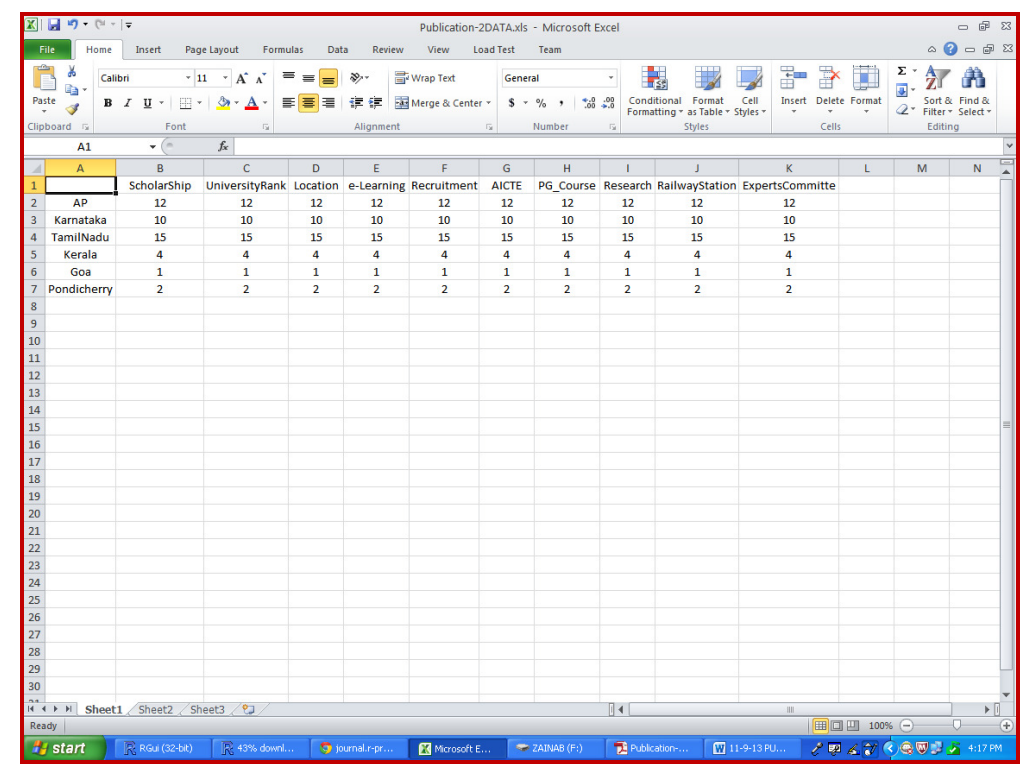

Fig 16: Shows how the database is integrated with South zone $(n=165)$

The above figure or datasheet shows these 6 South nodes are integrated with fields of prototype database which is alredy discussed in [6],pp. 9 by authors.In this case 50\% availablility is applied to all available datafileds as shown in fig 16.

\subsubsection{Local clusters implementation with $R$ datamining tool}

$\mathrm{R}$ is also one of the very popular datamining tool in the market especially for Education and Research.Using R we can implement Fuzzy logic and Neural networks also and these two are now out of scope for our scope.

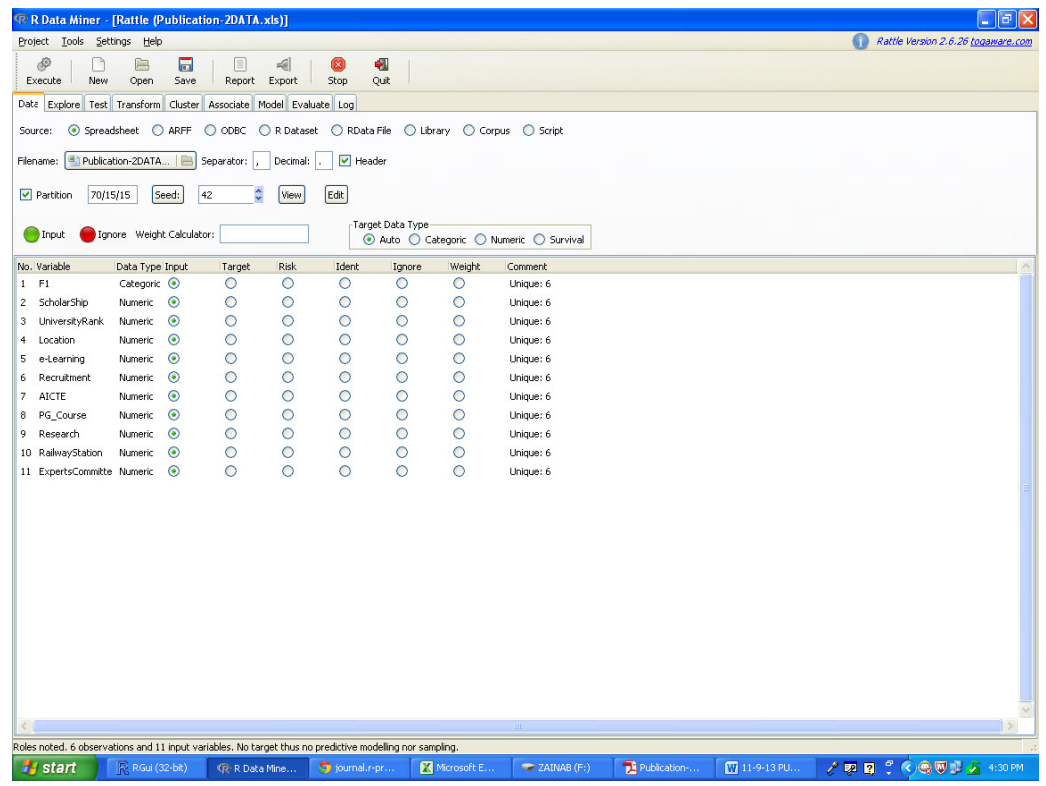

Fig 16: Shows data is loaded into R. 
First field is created by tool itself as default and its type is 'Category' and fields type are 'Numeric' as shown in above figure.

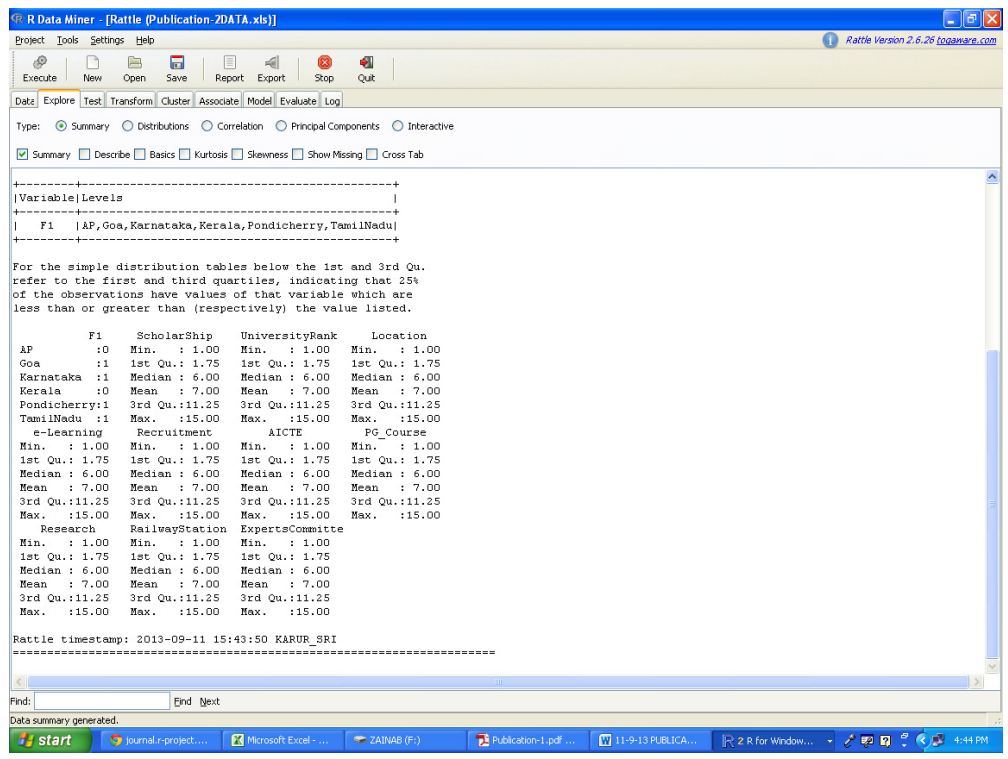

Fig 17: Shows all Statistical values are calculated for all South nodes wrt default node

From the figure 17 it obseverd that all statistical values are calculated such as min,max,mean,median etc. with respect to default field 'Categary'.This 'Category' type is useful for tool implementation only.

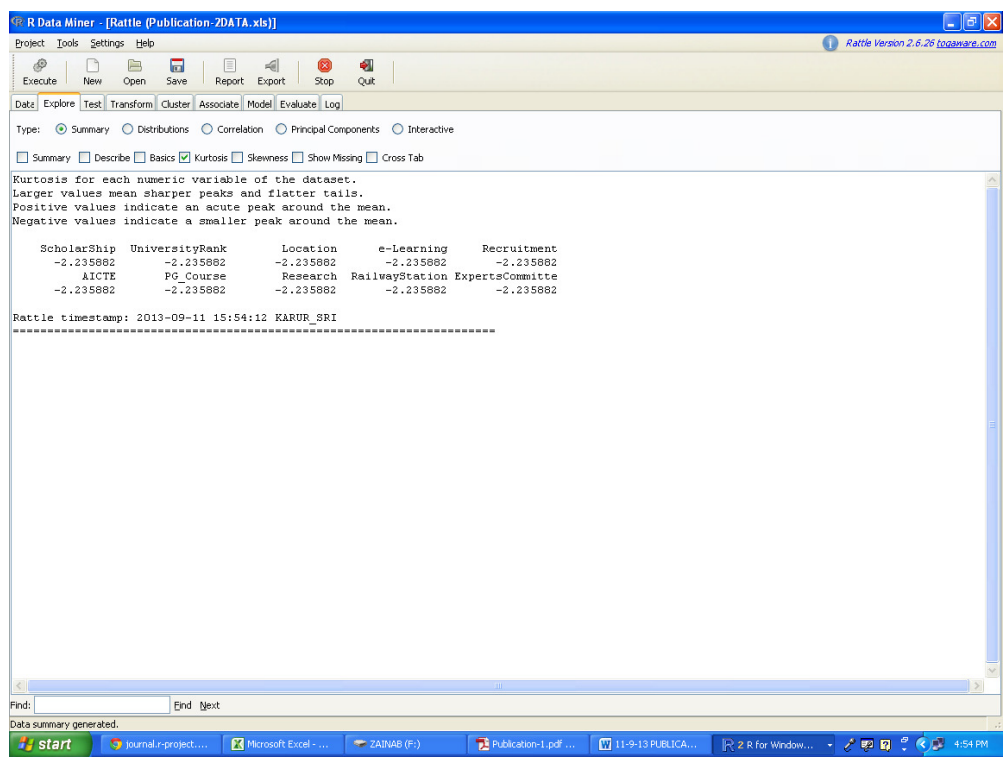

Fig 18. Shows Kurtosis of expected data 
Kurtosis for each numeric variable of the dataset.Larger values mean sharper peaks and flatter tails. Positive values indicate an acute peak around the mean.Negative values indicate a smaller peak around the mean.For a give dataset all Kurtosis values are -ve.It means that only small peaks are around the mean.

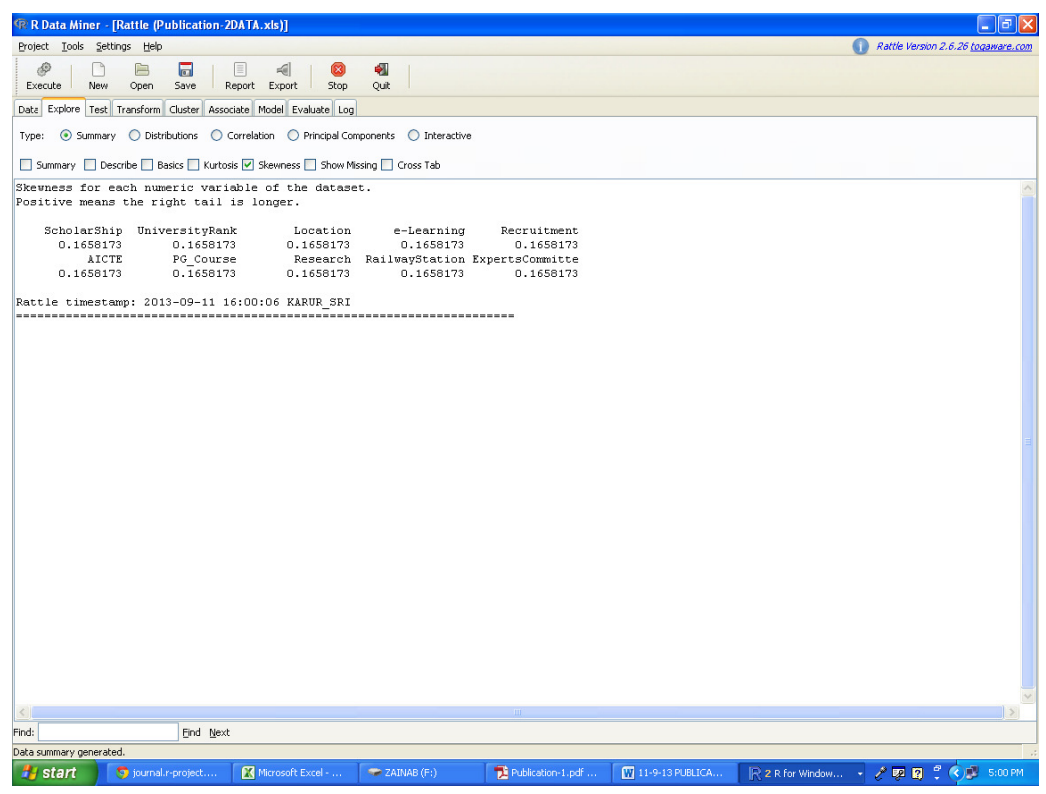

Fig 19. Shows Skewness of datasheet of values

Skewness for each numeric variable of the dataset.Positive means the right tail is longer.All datavalues are Positive only.It means right tail is longer.

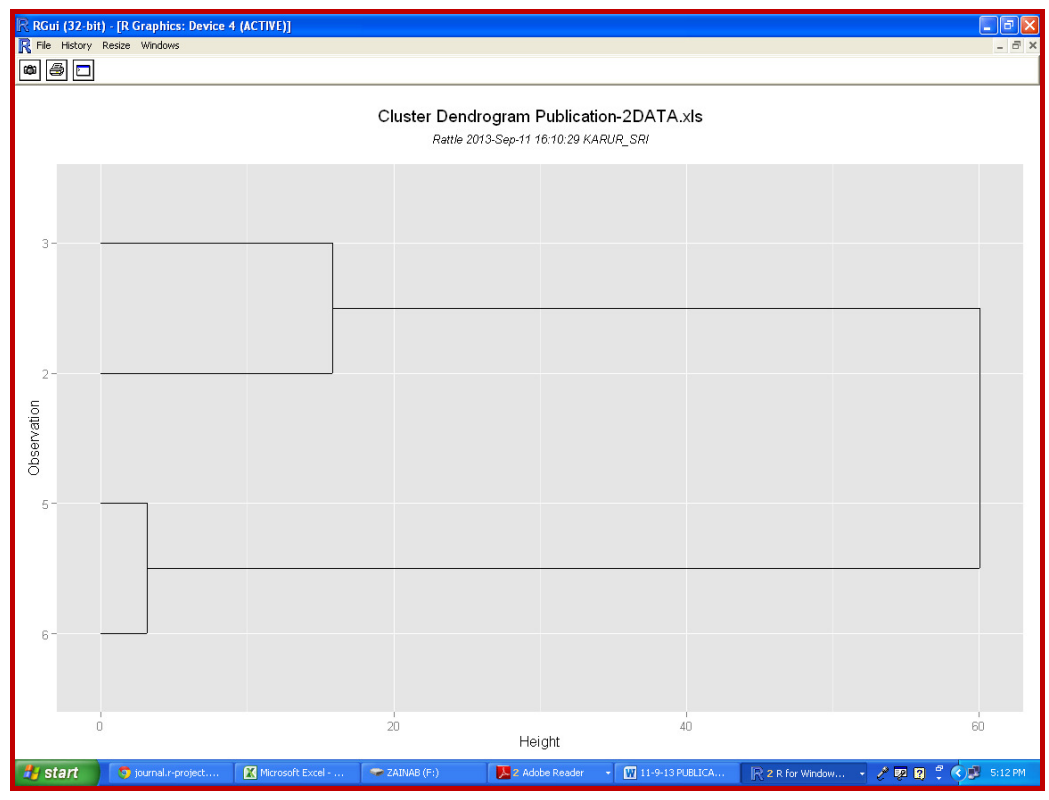

Fig 20. Hierachical Clustering for local system with height 60. 
International Journal of Artificial Intelligence \& Applications (IJAIA), Vol. 4, No. 5, September 2013

Hierachical Cluster Call:hclusterpar( $\mathrm{x}=$ na.omit(crs\$dataset[crs\$sample, crs\$numeric]), method $=$ "euclidean", link $=$ "ward", nbproc $=1$ ) Cluster method : ward Distance : euclidean

Number of objects: 4.K-Means should not work on other than 'Numeric' type.

\section{Conclusion}

India has very large of educational resources for higher education which have 611 Universities and approximately 32,000 UGC recognized colleges.UGC has a policy in their 12th FYP which tells about University-College clustering. We can split the total area into different geographical groups like South, North, East, West and North East or any other parameters. It is very necessary to construct the clusters on the basis of local clusters. Since local systems are only handle the abstract very efficiently. If the sample size is very big without abstract we can not implement any policy. If local systems are constructed efficiently abstract systems and prototype systems are automatically become idle and immediately local clusters are communicated with central clusters. Due to uncertainty in large database or policies at strategic level it is advisable to create prototype database model as a local cluster databses.In market lot of reputed companies are available for all types of technical cluster creation and maintenance. Strategic level is more complicated than operational level regarding local clusters construction. In future research we can concentrate on local clusters with respect to "Curve fitting "Method

\section{ACKNOWLEDGEMENTS}

The authors would like to thanks for all teachers from school level to Research level,and non teaching staff also.

\section{REFERENCES}

[1] http://ibr.hi.is/sites/ibr.hi.is/files/Location__Competition_and_Economic_Development_Local_ Clusters_in_a_Global_Economy.pdf

[2] http://ro.uow.edu.au/commwkpapers/125

[3] http://www.utoronto.ca/isrn/publications/WorkingPapers/Working01/Mytelka01_Clusters.pd

[4] http://www.ugc.ac.in/ugcpdf/740315_12FYP.pdf.

[5] http://citeseerx.ist.psu.edu/viewdoc/download?doi=10.1.1.1.1856\&rep=rep1\&type=pdf

[6] http://airccse.org/journal/ijaia/papers/4413ijaia12.pdf

[7] http://www.ipedr.com/vol3/61-M10055.pdf

[8] http://www.ey.com/Publication/vwLUAssets/Higher_Education_in_India/\$File/EYFICC_Higher_Education_Report_Nov12.pdf

[9] http://en.wikipedia.org/wiki/List_of_universities_in_India

[10] http://www-sre.wu-wien.ac.at/ersa/ersaconfs/ersa02/cd-rom/papers/270.pdf

[11] http://hcd.ucdavis.edu/faculty/webpages/kenney/articles_files/Sohn,\%20Kenney\%20KU.pdf

[12] http://fmc.org.in/History.aspx

[13] http://business.gov.in/outerwin.php?id=http://www.dcmsme.gov.in/clusters/clus/smelist.htm

[14] http://www.caps.am/data.php/853.pdf

[15] http://www.doc.ic.ac.uk/ ccris/ftp/asl-short.pdf

[16] www.home.furb.br/wilhelm/COMPETIV/Porter_Cluster3.doc 
International Journal of Artificial Intelligence \& Applications (IJAIA), Vol. 4, No. 5, September 2013

\section{AUTHORS:}

Mr.Srinatha Karur is Research scholar and has both academic and technical profile. He completed M.CA from Gulbarga University campus on 1997- May, M.Tech (IT) from Punjabi University, GGSIIT, 2002-04, Patiala, India, and M.Phil. from Global University, Kohima, India, 2009 December.At present author is working as Oracle DBA in Govt Engineering College,Ibra,Sultanate of Oman.Post box: 327.

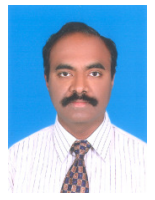

Prof.M.V.Raman Murthy is senior professor and Director for Department of Computer Science, Osmaina University, Hyderabad, India. He is author of core programming languages and international Publications on different applications. His profile shows his complete grip on Academic,Administration and Technical fields.He completed lot of foreign assigments in terms of proessional challenges.

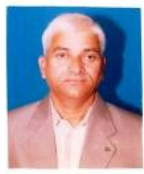

